J. Biosoc. Sci., (2013) 45, 331-344, (C) Cambridge University Press, 2013. The online version of this article is published within an Open Access environment subject to the conditions of the Creative Commons Attribution-NonCommercial-ShareAlike licence <http://creativecommons.org/licenses/ by-nc-sa/3.0/>. The written permission of Cambridge University Press must be obtained for commercial re-use.

doi:10.1017/S0021932012000855 First published online 14 Jan 2013

\title{
THE INFLUENCE OF GENDER ATTITUDES ON CONTRACEPTIVE USE IN TANZANIA: NEW EVIDENCE USING HUSBANDS' AND WIVES' SURVEY DATA
}

\author{
GEETA NANDA, SIDNEY RUTH SCHULER AND RACHEL LENZI
}

\author{
FHI 360, Washington, DC, USA
}

\begin{abstract}
Summary. This paper explores the hypothesis that gender attitude scales (which measure the degree of equity in gender attitudes) are associated with contraceptive use. Four hundred male and female respondents (200 couples) were interviewed using a pre-tested, structured questionnaire. Analyses included comparisons of means and prevalence rates on gender equity indicators, other related factors and socio-demographic characteristics; $t$-tests to compare mean scores on each gender scale for wives and husbands to identify any significant differences; chi-squared tests to compare associations between individual attributes, attitudes and contraceptive use; and multivariate logistic regression to examine associations between each gender scale and contraceptive use. The findings revealed that, on average, wives endorsed more inequitable gender attitudes compared with husbands on all gender attitude scales. For wives, more equitable gender attitudes were positively associated with contraceptive use. For husbands, the role of gender attitudes had no significant association with wives' reported contraceptive use. Family planning programmes that aim to challenge inegalitarian gender norms should not overlook women in their efforts since both men and women often accept and support inequality in a social system and, in some cases, it may be women's gender attitudes that most influence family planning decisions.
\end{abstract}

\section{Introduction}

Patriarchal gender norms and unequal power relations between men and women may function as barriers to contraceptive use by supporting pronatal attitudes and control over women by men, limiting women's decision-making power and inhibiting their access to resources, information and services. Gender norms and unequal power relations play an important role in reproductive decision-making since men's and women's approval and demand for use of contraception may diverge, with women's non-use of contraception, or sometimes their covert use, as potential consequences (Blanc, 2001). Numerous studies have found that women's empowerment or autonomy is associated with lower fertility and/or greater contraceptive use (e.g. Schuler \& Hashemi, 1994; Gage, 1995; 
Morgan \& Niraula, 1995; Govindasamy \& Malhotra, 1996; Schuler et al., 1997; Do \& Kurimoto, 2012). In other research, perceived spousal disapproval was found to be enough to increase unmet need for family planning reported by wives (Wolff et al., 2000), and lack of direct couple communication about reproductive intentions has been linked to unmet need or inaccurate reports about partners' approval or disapproval of family planning (Wolff et al., 2000; DeRose et al., 2004).

While there is evidence that programmes that use a gender-transformative approach (that is, programmes that go beyond accommodation and seek to change inequitable gender norms) can lead to improved reproductive health outcomes (WHO, 2007; Rottach et al., 2009; Greene \& Levack, 2010), most of the programmes that have documented success in transforming gender norms have focused on HIV/AIDS or genderbased violence, including Tuelimishane (Tanzania) (Maganja et al., 2007; Mbwambo \& Maman, 2007), Stepping Stones (South Africa) (Jewkes et al., 2006, 2007, 2008) and Programme H (Brazil and India) (Pulerwitz et al., 2006; Verma et al., 2006). Other programmes have worked with youth using multi-sectoral life skills approaches, including ISHRAQ (Egypt) (Save the Children, 2004; Brady et al., 2007) and First-time Parents (India) (Population Council, 2006; Santhya \& Haberland, 2007; Santhya et al., 2008), rather than focusing on family planning.

The links between gender attitudes and reproductive health outcomes may seem apparent to many, but the case for incorporating gender-transformative interventions into health and population programmes could be further strengthened by increasing the evidence base regarding the links between gender attitudes and contraceptive use. Save the Children's Male Motivator Project in Malawi, which did directly measure gender attitudes, resulted in significant increases in contraceptive use, but increases in gender-equitable attitudes among husbands in the intervention group were not significantly greater than increases in the control group (Shattuck et al., 2011). Additionally, as the results were based on husbands' reports of wives' contraceptive use, there are questions about the reliability of the findings (Becker \& Costenbader, 2001). However, later qualitative work with wives of men who participated in the intervention did reveal perceived improvements in spousal communication and an increase in shared decisionmaking, which women said directly contributed to their family planning use (Hartmann et al., 2012).

Additional programmes that have successfully integrated a gender perspective into interventions to prevent unintentional pregnancies include Together for a Happy Family (Jordan) (JHUCCP, 2003), PRACHAR (India) (Wilder et al., 2005; Daniel et al., 2008), REWARD (Nepal) (CREHPA, 2002; CEDPA, 2005), Women's Empowerment Model to Train Midwives and Doctors (Afghanistan) (Family Health Alliance, 2007; Salke, 2007) and PROCOSI (Bolivia) (Palenque et al., 2004, 2007). However, many of these interventions either did not directly measure the impact on gender or showed only modest changes in gender attitudes (Rottach et al., 2009).

\section{Study objectives}

Although there is an evolving field of research examining health implications of gender norms and attitudes, less attention has been made to the effects of gender attitudes and gender-related behaviours on contraceptive use specifically (Rottach et al. 2009). 
The following analysis tests the hypothesis that gender attitude scales (which measure the degree of equity in gender attitudes) are associated with contraceptive use. The objectives were to: (1) determine which of four gender attitude scales, if any, predict contraceptive use; and (2) determine whose gender attitudes, if anyone's, predict contraceptive use - husband's and/or wife's. An implicit assumption is that gender-equitable behaviour is reflected in stated attitudes and that a correlation between equitable attitudes and contraceptive use constitutes evidence (though not conclusive) that improvements in gender equity may lead to increases in contraceptive use.

\section{Methods}

\section{Data}

The data are from an intervention study implemented by the Communication for Change (C-Change) project that aimed to test the effectiveness of radio programming addressing gender norms in support of a community-based contraceptive distribution programme implemented by the Tanzania Marketing and Communication Company (T-MARC) and the Private Nurses and Midwives Association of Tanzania (PRINMAT), a network of privately run clinics. The larger quasi-experiment tests the hypotheses that: (1) intensive radio campaign with gender-integrated family planning messaging affects gender equity attitudes; (2) gender-integrated messages have greater impact on community-based contraceptive distribution programme method uptake than nongendered messages; and (3) gender equity is related to family planning use by couples. The overall findings of the odds ratio (OR) study and details of the methodology will be published elsewhere.

This analysis uses data from the baseline household survey on contraceptive use, conducted in 2009 in Dodoma and Mwanza regions in Tanzania, which was carried out as part of the intervention study. The survey includes questions on attitudes about gender, as well as family planning knowledge, attitudes and behaviour. This paper focuses on the total sample of 400 respondents (200 male-female couples, either married or co-habiting; husbands and wives were interviewed separately), ranging in age from 15 to 49 , including both users and non-users of family planning. The interviews were conducted in Swahili. Institutional Review Board approval was obtained both in the United States and in Tanzania.

\section{Measures}

For this paper, the main outcome of interest is current contraceptive use as reported by wives. In using wives' reports, the guidance of Becker \& Costenbader (2001) is followed, which was adopted by the DHS in 2000. Additionally, in Tanzania, male method use was only $2.3 \%$ in 2010 (National Bureau of Statistics (NBS) [Tanzania] \& ICF Macro, 2011), and there is some evidence of women using contraceptives without telling their husbands (Becker \& Costenbader, 2001; Schuler et al., 2011). The question asked in the survey was 'Are you currently doing something or using any method to delay or avoid getting pregnant?' The responses were coded into a dichotomous variable, whereby ' 0 ' indicates not using a method, and ' 1 ' indicates use of any contraceptive method, including both modern and traditional methods. As an additional point of 
interest, it was noted that the kappa statistic for women's and men's reported contraceptive use was 0.56 , indicating a moderate level of agreement on this indicator.

The key explanatory variables of interest are four scales measuring gender attitudes. Three scales were adapted from questions included in the standard DHS questionnaire, which are intended to measure 'the extent of women's acceptance of norms that justify men's control over women' (Upadhyay \& Karasek, 2010) and the fourth is the Gender Equitable Men (GEM) scale, which is a standardized measure of attitudes toward gender norms in intimate relationships (see Pulerwitz \& Barker, 2008, for more details).

The Gender Equitable Men (GEM) scale. The GEM scale is a 24-item scale measuring equitability of attitudes in intimate relationships across four domains, including violence, sexual relationships, reproductive health and disease prevention, and domestic chores and daily life. Respondents were asked about their agreement with a range of statements in each of these domains. For example, these include statements such as: 'there are times a woman deserves to be beaten', 'men need sex more than women do', 'a real man produces a male child', and 'a woman's role is taking care of her home and family'. Responses were classified into one of the following three categories: agree, partially agree and disagree. For each GEM scale item, a variable was constructed to capture the degree of equity in the attitude: the variable was coded as ' 1 ' to indicate the most equitable attitude, and ' 0 ' to indicate all other response options (i.e. agreement or partial agreement with the statement). A composite measure was constructed using a summated score for the GEM scale ranging from 0 to 24 , with 0 indicating the least gender-equitable attitudes and 24 indicating the highest level of gender-equitable attitudes. In addition, a categorical variable for the GEM scale was created using a trichotomy of low equity (score of 0 to 7), medium equity (score of 8 to 15) and high equity (score of 16 to 24$)$.

The Household Decision-Making scale. This scale was derived from DHS questions on women's role in household decision-making that are designed to measure attitudes towards women's degree of control over their environment in five areas. The question posed was 'In a couple, who do you think should have the greater say in each of the following decisions? - making large household purchases; making small daily household purchases; deciding when to visit family, friends or relatives; deciding what to do with money the woman earns from her work; and deciding how many children to have and when to have them?' Responses were classified into one of the following categories: husband, wife, equal, it depends and don't know. For each household decision, a variable was constructed to capture women's decision-making, alone or jointly with her husband; the variable was coded as ' 1 ' to indicate those who believe wives should clearly have a say (alone or jointly) in the household decision, and ' 0 ' to indicate all other response options. Again, a summated score was used as a composite measure for the household decision-making scale; scores ranged from 0 to 5 , with 0 indicating the least genderequitable attitudes and 5 indicating the highest level of gender-equitable attitudes related to household decision-making. A categorical variable for the Household DecisionMaking scale was created, whereby the variable was coded as ' 1 ' to indicate if the wife has a say (either alone or jointly) in all five decisions, and ' 0 ' if the wife has a say (either alone or jointly) in fewer than five decisions or no say in any decisions. 
The Attitudes Toward Wife Refusing Sex scale. This is the second scale derived from the DHS. It measures acceptance of four hypothetical scenarios under which a wife may be considered justified in refusing to have sex with her husband. The question from the survey is 'Husbands and wives/partners don't always agree on everything. Please tell me if you think a wife/partner is justified in refusing to have sex with her husband/partner when: she suspects her husband has a sexually transmitted disease; she suspects her husband has sex with women other than his wife; she has recently given birth within the last 6 weeks or has not fully recovered; she is tired and not in the mood.' Responses were classified into yes (coded as ' 1 ') and no (coded as ' 0 '). Similar to the composite measure for household decision-making as described above, a summated score ranging from 0 to 4 was constructed, with 0 indicating the least and 4 the most equitable attitudes. Again, a categorical variable was created for this scale such that the variable was coded as ' 1 ' if the respondent says the wife has the right to refuse sex for all four reasons given, and ' 0 ' if the respondent says the wife does not have the right to refuse sex for one or more of the reasons given.

The Attitudes Toward Wife Beating scale. The third scale derived from the DHS standard questionnaire measures acceptance of five hypothetical scenarios under which a husband is justified in hitting or beating his wife. The question asked is 'Sometimes, a husband is annoyed or angered by what his wife/partner does. In your opinion, is a husband/partner justified in hitting or beating his wife/partner in the following situations: if she goes out without telling him; if she neglects the children; if she argues with him; if she refuses to have sex with him; if she burns the food?' Responses were classified into one of the following categories: yes, no, it depends and don't know. For each item, the variable was coded as ' 1 ' for a 'no' response, indicating that a husband/ partner was not justified in hitting or beating his wife/partner in that situation, and ' 0 ' to indicate all other response options. The summated score ranged from 0 to 5 , with 0 indicating the least gender-equitable attitudes and 5 indicating the most gender-equitable attitudes. A categorical variable for the Attitudes Toward Wife Beating scale was used as follows: one or more of the five reasons for wife beating are justified (coded as ' 0 '), and none of the reasons for wife beating was justified (coded as ' 1 ').

In addition, the analyses included the following socio-demographic variables that served as controls: current age, education, number of living children and region of residence.

\section{Statistical analysis}

Analysis was conducted in several steps. The first stage of the analysis focused on describing the characteristics of the matched couple sample. Means and prevalence rates on gender equity indicators, other related factors and socio-demographic characteristics were estimated. The levels of response to each item in the gender scales were examined separately for wives and husbands (results not shown), as well as the overall means on each scale. Statistical tests ( $t$-tests) were carried out to compare mean scores on each gender scale for wives and husbands to identify any significant differences. The next part of the analysis investigated associations between individual attributes, attitudes and contraceptive use using chi-squared tests to compare findings across husbands and 
wives. In the final stage of analysis, multivariate logistic regression techniques were employed to examine the associations between each gender scale and contraceptive use. Models were run separately for male (husbands) and female (wives) respondents. All analyses were performed using SPSS version 17.

\section{Results}

\section{Sample characteristics}

Table 1 shows the percentage distribution of selected socio-demographic and other background variables for husbands and wives in the baseline sample. The variable distributions indicate husbands had more education than their wives: $84 \%$ and $73.5 \%$, respectively, who have completed primary school or higher. Husbands in this sample also tended to be older than wives with a mean age of 33 years for husbands and 27 years for wives. Similarly, husbands had higher levels of media exposure compared with wives: $58 \%$ of husbands and $41 \%$ of wives reported reading the newspaper, and $98 \%$ and $94.5 \%$, respectively, listened to the radio. The large majority of male and female respondents were Christian. Most respondents reported having three or more children. Women reported relatively high current use of any method of family planning at $45.5 \%$.

Table 1. Characteristics of sample, Dodoma and Mwanza regions, Tanzania, 2009

\begin{tabular}{lcc}
\hline Variable & $\begin{array}{c}\text { Wives } \\
(n=200)\end{array}$ & $\begin{array}{c}\text { Husbands } \\
(n=200)\end{array}$ \\
\hline Age & & \\
$15-29$ years & $66.0 \%$ & $31.5 \%$ \\
$30-49$ years & $34.0 \%$ & $68.5 \%$ \\
Mean & 27.4 years & 33.2 years \\
Education & & \\
No education & $12.5 \%$ & $3.0 \%$ \\
Some primary & $14.0 \%$ & $13.0 \%$ \\
Complete primary & $63.5 \%$ & $67.0 \%$ \\
Post-primary & $10.0 \%$ & $17.0 \%$ \\
No. living children & & \\
None & $7.5 \%$ & $6.5 \%$ \\
1 & $21.5 \%$ & $21.5 \%$ \\
2 & $26.5 \%$ & $24.5 \%$ \\
3 or more & $44.5 \%$ & $47.5 \%$ \\
Religion & & \\
Christian & $74.5 \%$ & $69.5 \%$ \\
Muslim & $25.0 \%$ & $29.5 \%$ \\
Traditional & $0.5 \%$ & $1.0 \%$ \\
Exposure to media & & \\
Reads newspaper & $41.0 \%$ & $58.0 \%$ \\
Listens to radio & $94.5 \%$ & $98.0 \%$ \\
Current contraceptive use & & \\
No & $54.5 \%$ & \\
Yes & $45.5 \%$ & \\
\hline & &
\end{tabular}


Table 2. Average gender scale scores for wives and husbands, Dodoma and Mwanza regions, Tanzania, 2009

\begin{tabular}{lcc}
\hline Gender attitude scale & Wives & Husbands \\
\hline Gender Equitable Men (GEM) scale (0 to 24$)$ & 9.0 & 9.4 \\
Household Decision-Making scale (0 to 5)* & 2.9 & 3.2 \\
Attitudes Toward Wife Refusing Sex scale (0 to 4) & 3.5 & 3.6 \\
Attitudes Toward Wife Beating scale (0 to 5)*** & 2.0 & 3.4 \\
\hline
\end{tabular}

$t$-test: ${ }^{*} p<0.05 ; * p<0.01 ; * * p<0.001$.

Table 3. Comparison of husbands' and wives' gender attitudes, Dodoma and Mwanza regions, Tanzania, 2009

\begin{tabular}{lcc}
\hline & $\begin{array}{c}\text { Wives } \\
(n=200) \\
\%\end{array}$ & $\begin{array}{c}\text { Husbands } \\
(n=200) \\
\%\end{array}$ \\
Variable & 36.5 & 38.0 \\
\hline GEM scale equity index** & 58.0 & 45.5 \\
$\quad$ Low equity & 5.5 & 16.5 \\
$\quad$ Moderate equity & 92.0 & 84.0 \\
$\quad$ High equity & 8.0 & 16.0 \\
Household Decision-Making scale* & & \\
$\quad$ Has say in fewer than 5 decisions or no say in any decisions & 25.5 & 27.5 \\
Has say (alone or jointly) in all 5 decisions & 74.5 & 72.5 \\
Attitudes Toward Wife Refusing Sex scale & & 69.5 \\
$\quad$ Wife does not have the right to refuse sex for one or more reasons & 94.5 & 6.5 \\
$\quad$ Wife has the right to refuse sex for all 4 reasons given & 5.5 & 30.5 \\
Attitudes Toward Wife Beating scale*** & & \\
$\quad$ One or more of the 5 reasons for wife beating are justified & \\
None of the reasons for wife beating is justified &
\end{tabular}

Pearson's $\chi^{2}$ test: ${ }^{*} p<0.05 ; * * p<0.01 ; * * *<0.001$.

\section{Gender attitudes}

Tables 2 and 3 describe the gender attitudes of respondents in order to assess how gender equitable husbands and wives were relative to each other. As shown in Table 2, average scores on all four gender attitude scales were compared with $t$-tests. Although scores overall tended to be at the lower end, suggesting support for many inequitable gender norms, husbands had higher average scores than wives on all four scales. Husbands' scores were significantly higher on the Household Decision-Making scale (3.2 compared with 2.9, $p<0.05$ ) and Attitudes Toward Wife Beating scale (3.4 compared with $2.0, p<0.001)$. 
As shown in Table 3, the four gender attitude scales were treated as categorical variables to indicate different levels of gender equity. Again, wives had less equitable gender attitudes compared with husbands on all gender scales. For example, for the GEM scale, husbands were significantly more likely than wives to fall into the highequity category $(16.5 \%$ compared with $5.5 \%, p<0.01)$. Similarly, among the three gender attitude scales derived from the DHS, there were significant differences between husbands and wives for the Household Decision-Making scale, with $16 \%$ of husbands compared with $8 \%$ of wives reporting that a woman should have a say (alone or jointly) in all five household decisions $(p<0.05)$, and the Attitudes Toward Wife Beating scale, with $30.5 \%$ of husbands compared with $5.5 \%$ of wives reporting that none of the reasons given for wife beating was justified $(p<0.001)$.

\section{The relationship among attributes, attitudes and use of family planning}

Separate logistic regression models were fitted for each of the four gender attitude scales, and these analyses were run separately for husbands and wives. The models control for age, education, the number of living children and region of residence. Tables 4 to 7 show the findings from the multivariable logistic regression analyses, including adjusted odds ratios and $95 \%$ confidence intervals.

In all models, the odds of contraceptive use increased with the number of living children reported by the respondent, although the effects were greater for women than for men. Region of residence was also associated with increased odds of contraceptive use in all models. Neither age nor education was significant in any of the models.

Table 4. Adjusted odds ratios (OR) and 95\% confidence intervals $(95 \% \mathrm{CI})$ of reporting contraceptive use by the GEM scale and socio-demographic factors, Dodoma and

Mwanza regions, Tanzania, 2009

\begin{tabular}{|c|c|c|}
\hline \multirow[b]{2}{*}{ Variable } & \multicolumn{2}{|c|}{ Adjusted OR (95\% CI) } \\
\hline & Husbands & Wives \\
\hline \multicolumn{3}{|l|}{ Age } \\
\hline \multicolumn{3}{|l|}{ 15-29 years (Ref.) } \\
\hline $30-49$ years & $1.24(0.60,2.59)$ & $1.12(0.53,2.39)$ \\
\hline \multicolumn{3}{|l|}{ Education } \\
\hline \multicolumn{3}{|c|}{ No education or some primary (Ref.) } \\
\hline Complete primary or higher & $1.65(0.65,4.23)$ & $1.65(0.78,3.51)$ \\
\hline \multicolumn{3}{|l|}{ No. living children } \\
\hline \multicolumn{3}{|l|}{ 0-1 (Ref.) } \\
\hline 2 & $2.76(1.17,6.53)^{*}$ & $4.37(1.78,10.76)^{* *}$ \\
\hline 3 or more & $2.94(1.27,6.80)^{*}$ & $5.74(2.20,14.97)^{* * *}$ \\
\hline \multicolumn{3}{|l|}{ Region } \\
\hline \multicolumn{3}{|l|}{ Mwanza (Ref.) } \\
\hline Dodoma & $4.20(2.10,8.42)^{* * *}$ & $7.06(3.24,15.38)^{* * *}$ \\
\hline GEM scale (continuous) & $1.01(0.96,1.07)$ & $1.11(1.01,1.21)^{*}$ \\
\hline
\end{tabular}


Table 5. Adjusted odds ratios (OR) and $95 \%$ confidence intervals $(95 \% \mathrm{CI})$ of reporting contraceptive use by the Household Decision-Making scale and sociodemographic factors, Dodoma and Mwanza regions, Tanzania, 2009

\begin{tabular}{llc}
\hline & \multicolumn{2}{c}{ Adjusted OR $(95 \% \mathrm{CI})$} \\
\cline { 2 - 3 } Variable & \multicolumn{1}{c}{ Husbands } & Wives \\
\hline Age & & \\
$\quad 15-29$ years (Ref.) & $1.25(0.60,2.60)$ & $1.10(0.52,2.32)$ \\
$\quad 30-49$ years & & \\
Education & & $1.74(0.83,3.63)$ \\
$\quad$ No education or some primary (Ref.) & $1.61(0.62,4.15)$ & \\
$\quad$ Complete primary or higher & & \\
No. living children & & \\
$\quad 0-1$ (Ref.) & $2.71(1.14,6.43)^{*}$ & $4.09(1.69,9.93)^{* *}$ \\
$\quad 2$ & $2.85(1.22,6.68)^{*}$ & $5.36(2.09,13.77)^{* * *}$ \\
$\quad 3$ or more & & \\
Region & & \\
$\quad$ Mwanza (Ref.) & & \\
$\quad$ Dodoma & $4.02(2.10,7.68)^{* * *}$ & $4.82(2.38,9.77)^{* * *}$ \\
Household Decision-Making scale (continuous) & $1.07(0.84,1.36)$ & $1.17(0.90,1.51)$ \\
\hline$* p<0.05 ; * * p<0.01 ; * * * p 0.001$. & &
\end{tabular}

Table 6. Adjusted odds ratios (OR) and 95\% confidence intervals (95\% CI) of reporting contraceptive use by the Attitudes Toward Refusing Sex scale and sociodemographic factors, Dodoma and Mwanza regions, Tanzania, 2009

\begin{tabular}{llc}
\hline & \multicolumn{2}{c}{ Adjusted OR (95\% CI) } \\
\cline { 2 - 3 } Variable & \multicolumn{1}{c}{ Husbands } & Wives \\
\hline Age & & \\
$\quad 15-29$ years (Ref.) & $1.22(0.58,2.54)$ & $1.14(0.54,2.42)$ \\
$\quad 30-49$ years & & \\
Education & & $1.82(0.87,3.84)$ \\
$\quad$ No education or some primary (Ref.) & $1.61(0.64,4.05)$ & \\
$\quad$ Complete primary or higher & & \\
No. living children & & \\
$\quad 0-1$ (Ref.) & $2.73(1.15,6.46)^{*}$ & $4.04(1.66,9.79)^{* *}$ \\
$\quad 2$ & $2.88(1.24,6.70)^{*}$ & $5.03(1.96,12.88)^{* *}$ \\
$\quad 3$ or more & & \\
Region & & \\
$\quad$ Mwanza (Ref.) & $3.81(1.98,7.35)^{* * *}$ & $5.48(2.70,11.16)^{* * *}$ \\
$\quad$ Dodoma & $1.22(0.79,1.86)$ & $0.78(0.57,1.08)$ \\
\hline Attitudes Toward Refusing Sex scale (continuous)
\end{tabular}

${ }^{*} p<0.05 ; * * p<0.01 ; * * *<0.001$. 
Table 7. Adjusted odds ratios (OR) and $95 \%$ confidence intervals ( $95 \% \mathrm{CI}$ ) of reporting contraceptive use by the Attitudes Toward Wife Beating scale and sociodemographic factors, Dodoma and Mwanza regions, Tanzania, 2009

\begin{tabular}{llc}
\hline & \multicolumn{2}{c}{ Adjusted OR (95\% CI) } \\
\cline { 2 - 3 } Variable & \multicolumn{1}{c}{ Husbands } & Wives \\
\hline Age & & \\
$\quad 15-29$ years (Ref.) & $1.26(0.60,2.62)$ & $1.07(0.50,2.28)$ \\
$\quad 30-49$ years & & \\
Education & & $1.54(0.72,3.27)$ \\
$\quad$ No education or some primary (Ref.) & & \\
$\quad$ Complete primary or higher & $1.77(0.71,4.46)$ & \\
No. living children & & \\
$\quad 0-1$ (Ref.) & $2.76(1.17,6.52)^{*}$ & $4.43(1.80,10.89)^{* *}$ \\
$\quad \begin{array}{l}2 \\
3 \text { or more }\end{array}$ & $2.98(1.28,6.93)^{*}$ & $5.52(2.13,14.30)^{* * *}$ \\
Region & & \\
$\quad$ Mwanza (Ref.) & & \\
$\quad$ Dodoma & & \\
Attitudes Toward Wife Beating scale (continuous) & $0.95(0.77,1.17)$ & $1.29(1.02,1.64) *$ \\
\hline$* p<0.05 ; * *<0.01 ; * * * p<0.001$. & &
\end{tabular}

For women, two of the four gender attitude scales - the GEM scale and the Attitudes Toward Wife Beating scale - were positively associated with contraceptive use. For men, none of the gender attitude scales was associated with contraceptive use, based on the wife's report (Tables 4-7).

\section{Discussion}

This study contributes to a growing body of couple studies on reproductive behaviour (see Becker \& Costenbader, 2001; DeRose, et al., 2004; Allendorf, 2007; Kulczycki, 2008), and is one of the first couple studies using the GEM scale to compare genderequitable attitudes of spouses. The analysis reveals new evidence regarding the influence of gender attitudes on contraceptive use, and underscores the need for information from both members of a couple. In general, wives had less equitable gender attitudes as compared with their husbands and, for three of the four scales examined, the differences were statistically significant (the GEM, Household Decision-Making and Attitudes Toward Wife Beating scales). Somewhat surprisingly, wives' gender attitudes predicted contraceptive use (as reported by wives) but husbands' gender attitudes did not. The more equitable a woman's gender attitudes, the more likely she was to be using a method of contraception. Age, parity and education are commonly accepted variables positively correlated with contraceptive use, but in this analysis, only parity was significantly correlated with contraceptive use, and highly so, showing that gender attitudes have predictive power even after controlling for known correlates of family planning. 
The study has several limitations, including its small sample size (200 couples), and the fact that the sample was drawn from only two areas of Tanzania (the sites of an intervention study), thus limiting generalizability. Sites were limited to districts in which T-MARC was collaborating with PRINMAT clinics in a community-based contraceptive distribution initiative, and where there was a local radio station willing to promote the community-based distributors. Additionally, there was unusually high contraceptive use among the sample, especially in one of the regions $(30 \%$ of female respondents in Mwanza, 61\% in Dodoma). This is taken into account by controlling for region. According to the 2010 DHS, current use of any method in these regions was reported as $15.2 \%$ in Mwanza and 28.4\% in Dodoma (NBS \& ICF Macro, 2011).

Although it cannot be demonstrated with this dataset, it is possible that, in reality, men's attitudes do not reflect a greater degree of gender equity than women's and that the data collected from men suffers from a higher degree of 'desirability bias' than the data from women. In other words, men may be more likely to report what they assume to be the more 'acceptable' responses from the perspective of the interviewer. If that is the case, the question of whether men's gender attitudes are associated with contraceptive use in this context is still open. Similar findings have been reported from research using matched couples in India where husbands had more equitable views of their wives' autonomy than their wives did (Jejeebhoy, 2002). There it appeared that husbands gave more 'acceptable' responses in the survey than when they were questioned in depth. In this study, unfortunately, neither male nor female participants were interviewed in depth, so it was not possible to determine levels of socially desirable responses. Similarly, a secondary analysis of survey data from monogamous couples in Malawi that looked at couple agreement on a range of issues, including ownership of household items, livestock, number of children, communication about fertility, family planning and AIDS, found that for many questions, when spouses' reports disagreed, husbands were more likely to answer 'yes' and wives 'no' when 'yes' was the answer that implied greater wealth, fertility or modernity (Miller et al., 2001).

\section{Conclusion}

While the primary arguments for pursuing gender transformative strategies in health and population programmes should be based on equity and human rights concerns, evidence that such strategies can also contribute to health and population objectives may help to strengthen and broaden commitment to them. The finding that contraceptive use is associated with gender-equitable attitudes among women suggests that one should not overlook women in the call to change male attitudes and support male involvement in reproductive health. Women as well as men often support inequality in a social system, and in this setting, family planning programmes that support genderequitable attitudes among women may help facilitate their use of contraception.

\section{Acknowledgments}

This study was made possible by the generous support of the American people through the United States Agency for International Development (USAID) under the terms of Cooperative Agreement No. GPO-A-00-07-00004-00. The contents are the responsibility 
of the C-Change program, managed by FHI 360, and do not necessarily reflect the views of USAID or the United States Government. The authors would also like to thank Jane Alaii, Jim Foreit and Elisabeth Rottach for their valuable assistance with the research design and T-MARC for facilitating the intervention study.

\section{References}

Allendorf, K. (2007) Couples' reports of women's autonomy and health-care use in Nepal. Studies in Family Planning 38(1), 35-46.

Becker, S. \& Costenbader, E. (2001) Husbands' and wives' reports of contraceptive use. Studies in Family Planning 32(2), 111-129.

Blanc, A. K. (2001) The effect of power in sexual relationships on sexual and reproductive health. Studies in Family Planning 32(3), 189-213.

Brady, M., Assaad, R., Ibrahim, B., Salem, A., Salem, R. \& Zibani, N. (2007) Providing New Opportunities to Adolescent Girls in Socially Conservative Settings: The ISHRAQ Program in Rural Upper Egypt. Population Council, New York.

Centre for Development and Population Activities (CEDPA) (2005) New Vision: Life Skills Education for Boys. CEDPA, Washington, DC.

Centre for Research on Environmental Health and Population Activities (CREHPA) (2002) Enabling Women for Reproductive Health: The REWARD Project. CEDPA, Washington, DC.

Daniel, E. E., Masilamani, R. \& Rahman, M. (2008) The effect of community-based reproductive health communication interventions on contraceptive use among young married couples in Bihar, India. International Family Planning Perspectives 34(4), 189-197.

DeRose, L. F., Dodoo, F. N., Ezeh, A. C. \& Owuar, T. O. (2004) Does discussion of family planning improve knowledge of partner's attitude toward contraceptives? International Family Planning Perspectives 30(2), 87-93.

Do, M. \& Kurimoto, N. (2012) Women's empowerment and choice of contraceptive methods in selected African countries. International Perspectives on Sexual and Reproductive Health 38(1), 23-33.

Family Health Alliance (2007) Clinical Family Planning/Reproductive health Training Program in Afghanistan. Family Health Alliance, Washington, DC.

Family Health International (FHI) (2011) Men's Involvement in Emergency Contraceptive Use in Ghana. FHI, Durham, NC.

Gage, A. (1995) Women's socioeconomic position and contraceptive behaviour in Togo. Studies in Family Planning 26(5), 264-277.

Govindasamy, P. \& Malhotra, A. (1996) Women's position and family planning in Egypt. Studies in Family Planning 27(6), 328-340.

Greene, M. E. \& Levack, A. (2010) Synchronizing Gender Strategies: A Cooperative Model for Improving Reproductive Health and Transforming Gender Relations. PRB, Washington, DC.

Hartmann, M., Gilles, K., Shattuck, D., Kerner, B. \& Guest, G. (2012) Changes in couples' communication as a result of a male-involvement family planning intervention. Journal of Health Communication: International Perspectives DOI: 10.1080/10810730.2011.650825.

Jejeebhoy, S. J. (2002) Convergence and divergence in spouses' perceptions on women's autonomy in rural India. Studies in Family Planning 33(4), 299-308.

Jewkes, R., Nduna, M., Levin, J., Jama, N., Dunkle, K., Khuzwayo, N., Koss, M. et al. (2006) A cluster randomized-controlled trial to determine the effectiveness of Stepping Stones in preventing HIV infections and promoting safer sexual behaviour amongst youth in the rural Eastern Cape, South Africa: trial design, methods and baseline findings. Tropical Medicine and International Health 11(1), 3-16. 
Jewkes, R., Nduna, M., Levin, J., Jama, N., Dunkle, K., Puren, A. \& Duvvury, N. (2008) Impact of Stepping Stones on HIV, HSV-2, and sexual behaviour in rural South Africa: cluster randomised controlled trial. British Medical Journal 337.

Jewkes, R., Nduna, M., Levin, J., Jama, N., Dunkle, K., Wood, K. et al. (2007) Evaluation of Stepping Stones: A Gender Transformative HIV Prevention Intervention: A Policy Brief. Medical Research Council, Pretoria.

Johns Hopkins University Centre for Communication Programs (JHUCCP) (2003) Men in Jordan Get Involved in 'Together for a Happy Family.' JHU Bloomberg School of Public Health, Baltimore, MD.

Kulczycki, A. (2008) Husband-wife agreement, power relations and contraceptive use in Turkey. International Family Planning Perspectives 34(3), 127-137.

Maganja, R. K., Maman, S., Groves, A. \& Mbwambo, J. K. (2007) Skinning the goat and pulling the load: transactional sex among youth in Dar es Salaam. AIDS Care 19(8), 974-981.

Mbwambo, J. \& Maman, S. (2007) HIV and Violence Prevention. Horizons Final Report. Population Council, Washington, DC.

Miller, K., Zulu, E. M., \& Watkins, S. C. (2001) Husband-wife survey responses in Malawi. Studies in Family Planning 32(2), 161-174.

Morgan, S. P. \& Niraula, B. B. (1995) Gender inequality and fertility in two Nepali villages. Population and Development Review 21(3), 541-561.

National Bureau of Statistics (NBS) [Tanzania] \& ICF Macro (2011) Tanzania Demographic and Health Survey, 2010. NBS and ICF Macro, Dar es Salaam.

Palenque, E., Monano, L., Vernon, R., Gonzales, F., Riveros, P. \& Bratt, J. (2004) Effects and Costs of Implementing a Gender-Sensitive Reproductive Health Program. Frontiers Final Report. Population Council, Washington, DC.

Palenque, E., Riveros Hamel, P., \& Vernon, R. (2007) Consolidating a Gender Perspective in the PROCOSI Network. Frontiers Final Report. Population Council, Washington, DC.

Population Council (2006) Meeting the Health and Social Needs of Married Girls in India: The First Time Parents Project's Implementation and Reach. Population Council, New Delhi.

Pulerwitz, J. \& Barker, G. (2008) Measuring attitudes toward gender norms among young men in Brazil: development and psychometric evaluation of the GEM Scale. Men and Masculinities 10(3), 322-338.

Pulerwitz, J., Barker, G., Segundo, M. \& Nascimento, M. (2006) Promoting More Gender-equitable Norms and Behaviours among Young Men as an HIV|AIDS Prevention Strategy. Horizons Program, Washington, DC.

Rottach, E., Schuler, S. R. \& Hardee, K. (2009) Gender Perspectives Improve Reproductive Outcomes: New Evidence. PRB, Washington, DC.

Salke, T. R. (2007) Lessons from the field: using a women's empowerment model to train midwives and doctors in Afghanistan. Presentation at the 2007 American Public Health Association Conference. Family Health Alliance, Washington, DC.

Santhya, K. G. \& Haberland, N. (2007) Empowering Young Mothers in India: Results of the Firsttime Parents Project. Population Council, New York.

Santhya, K. G., Haberland, N., Das, A. et al. (2008) Empowering Married Young Women and Improving their Sexual and Reproductive Health: Effects of the First-time Parent Project. Population Council, New Delhi.

Save the Children (2004) ISHRAQ: Safe Places for Out of School Adolescent Girls to Learn, Play and Grow. Empowering Rural Girls in Egypt. Save the Children, Westport, CT.

Schuler, S. R. \& Hashemi, S. M. (1994) Credit programs, women's empowerment, and contraceptive use in rural Bangladesh. Studies in Family Planning 25(2), 65-76. 
Schuler, S. R., Hashemi, S. M. \& Riley, A. P. (1997) The influence of changing roles and status in Bangladesh's fertility transition: evidence from a study of credit programs and contraceptive use. World Development 25(4), 563-575.

Schuler, S., Rottach, E. \& Mukiri, P. (2011) Gender norms and family planning decision-making in Tanzania: a qualitative study. Journal of Public Health in Africa 2(2), 102-107.

Shattuck, D., Kerner, B., Gilles, K., Hartmann, M., Ng'ombe, T. \& Guest, G. (2011) Encouraging contraceptive uptake by motivating men to communicate about family planning: the Malawi male Motivator Project. American Journal of Public Health 101(6), 1089-1095.

Upadhyay, U. D. \& Karasek, D. (2010) Women's Empowerment and Achievement of Desired Fertility in Sub-Saharan Africa. DHS Working Paper No. 80. ICF Macro, Calverton, MD.

Verma, R., Pulerwitz, J., Mahendra, V. S., Khandekar, S., Barker, G., Fulpagare, P. \& Singh, S. K. (2006) Challenging and changing gender attitudes among young men in Mumbai, India. Reproductive Health Matters 14(28), 135-143.

Wilder, J., Masilamani, R. \& Daniel, E. E. (2005) Promoting Change in the Reproductive Behaviour of Youth: Pathfinder International's PRACHAR Project. Pathfinder International, New Delhi.

Wolff, B., Blanc, A. K. \& Ssekamatte-Ssebuliba, J. (2000) The role of couple negotiation in unmet need for contraception and the decision to stop childbearing in Uganda. Studies in Family Planning 31(2), 124-137.

World Health Organization (2007) Engaging Men and Boys in Changing Gender-Based Inequity in Health: Evidence from Programme Interventions. WHO, Geneva. 